\title{
Arbor
}

\section{El tercer mundo y las Fuerzas Armadas}

\author{
Juan Carlos Domingo Guerra
}

Arbor CLXV, 651 (Marzo 2000), 415-443 pp.

Que los Estados Unidos de Norteamérica no pertenecen al Tercer Mundo es bastante obvio. Pero, no parece que pueda irse mucho más lejos en esta clase de generalizaciones cuando se habla del Tercer Mundo. De hecho, el sistema de clasificación de la Organización de Cooperación y Desarrollo Económicos cita a España entre estos países - los pertenecientes al Tercer Mundo- bajo la rúbrica de «en vías de industrialización». Diez son, además de España, los países que la OCDE clasifica como NIC,s (Newly Industrialising Countries), estando entre ellos Yugoslavia, Corea del Sur y Portugal ${ }^{1}$.

No se trata de discutir ahora qué países deben o no estar incluidos en cada grupo. Se trata solamente de constatar la dificultad de establecer criterios fiables, universalmente admitidos, que permitan agrupar entidades estatales de acuerdo a similares características, lo que haría posible tanto su análisis como el de sus agregados.

Los intentos por homogeneizar tan compleja realidad han sido infinitos. Además del ya mencionado, Naciones Unidas dispone de su propia clasificación -44 países calificados por su menor desarrollo, 88 países en vías de desarrollo y 13 más pertenecientes a la OPEP-; el Banco Internacional para la Reconstrucción y el Desarrollo, el suyo, mientras otras organizaciones o instituciones hacen sus propios ensayos.

La mayor parte de estas clasificaciones están basadas en criterios principalmente económicos, quizás porque fue desde esta disciplina desde la que se hicieron los primeros esfuerzos para aprehender y corregir una realidad que se mostraba extremadamente rigurosa para un $24 \%$ de la población mundial, la que vive en la indigencia.

No fue, sin embargo, hasta que el Programa de las Naciones Unidas para el Desarrollo (PNUD) elaboró el Indice de Desarrollo Humano 


\section{Juan Carlos Domingo Guerra}

- HDI en sus siglas en inglés- cuando se hace un intento serio de ir más allá de la información que proporcionaban los indicadores económicos clásicos, como los basados en el PIB. El HDI cuenta entre sus agregados factores que conforman directamente lo que se entiende como calidad de vida - esperanza de vida al nacer, índice de esperanza de vida o PIB real per cápita-, y otros que constituyen los fundamentos de un futuro más esperanzador - tasa bruta de matriculación combinada en centros escolares o índice de escolaridad-. En 1998, este índice relacionaba 174 naciones que lideraba Canadá — con un HDI de 0,960-, y tenía el triste honor de cerrar Sierra Leona (0,185). España, por ejemplo, se encontraba situada en el puesto undécimo gracias a un HDI de 0.935 , por delante de países como Bélgica o el Reino Unido ${ }^{2}$.

En cualquier caso, falta todavía hacer un intento por introducir en estas clasificaciones algunos aspectos mensurables - como el número de libros editados o el de funciones de teatro representadas-; y otros difíciles de traducir en lenguaje matemático, como tiempo dedicado al ocio, a la lectura o a conversar; todos ellos, unos y otros, más relacionados con el nivel de satisfacción individual que aquellos que reflejan exclusivamente la capacidad productiva de una sociedad.

Con independencia de las dificultades apuntadas, es preciso dedicar un cierto esfuerzo a identificar aquellas características que le puedan ser comunes a los Países en Vías de Desarrollo (PVD) y que permitirán extraer algunas conclusiones sobre el papel que desempeñan sus fuerzas armadas. M. Todaro identifica siete categorías ${ }^{3}$ : bajo nivel de vida, bajo nivel de productividad, altas tasas de natalidad, altos niveles de paro y empleo encubierto, dependencia del sector agrícola, preponderancia de mercados imperfectos e información limitada, dependencia y vulnerabilidad en las relaciones exteriores. Sin embargo, sería desconocer la realidad no subrayar la importancia que en la mayor parte de estos países tiene la inestabilidad política, alimentada en la insatisfacción de la población; y la dificultad de invertir en educación recursos escasos que son imprescindibles, la mayor parte de las veces, para garantizar la supervivencia. Es, en los países más desfavorecidos, donde mayor proporción de la población infantil trabaja en actividades marginales debido, en muchos casos, a la dificultad de que la unidad familiar prescinda de una fuente de ingresos complementaria, por muy exiguos que estos sean.

La actitud ante el desarrollo es otro aspecto a tomar en consideración. Afectada fundamentalmente por factores geográficos - en el sentido considerado por Huntington-, la educación y las creencias religiosas, el resultado de la inmersión cultural que se produjo durante etapas co- 


\section{El tercer mundo y las Fuerzas Armadas}

loniales permite reconocer distintos modelos de compromiso con el progreso. Por último, y en aquellos casos en los que la realidad estatal se asentó sobre una sociedad pluriétnica, el mayor o menor éxito en comprometer a los diferentes grupos humanos en un proyecto común ha constituido un definitivo multiplicador de la estabilidad social. Baste recordar, en lo que se refiere a dificultades añadidas que son inherentes a este último aspecto - la pluralidad étnica-, el mosaico que constituyen la mayor parte de las repúblicas caucásicas donde, por citar un caso extremo, en Daguestán conviven aproximadamente 30 grupos étnicos, cada uno de ellos con su propio idioma.

\section{El dramatismo de las desigualdades}

Quizá la mayor diferencia entre países ricos y pobres es que ésta, la diferencia, es mayor cada vez. Desde 1970, año en el que la proporción del volumen de ingresos entre el $20 \%$ más rico y más pobre de la población mundial era de 30 a 1, hasta 1991 en el que esa proporción había crecido hasta alcanzar un 61 a $1^{4}$, la fractura entre unos y otros no ha hecho más que aumentar. Pero otras consideraciones habrán de hacerse si se trata de buscar causas de inestabilidad.

Debe bucearse en los centros de documentación si se quiere obtener la relación de países clasificados según el índice de desarrollo humano. El HDI no se publica en bandos o ayuntamientos, así que no afecta a la propia estima de los ciudadanos. De otro modo, el grado de satisfacción relativa de los pueblos no está directamente influido por el puesto que se ocupe en ésta u otra relación. Sin embargo, la distribución interna de la riqueza sí afecta directamente a la estabilidad de las naciones. Aquellos que hayan tenido la oportunidad de viajar por América del Sur habrán podido ser testigos de algunos de los ejemplos más dramáticos de distribución asimétrica de recursos: los «ranchitos». Emplazados rodeando las grandes capitales - como en Caracas o Río de Janeiro- y, en algún caso, muy próximos a barrios residenciales, constituyen conjuntos de infraviviendas que difícilmente pueden ser consideradas incluso como tales. No se trata solamente de estar por debajo de los 370 U.S. \$ anuales de renta per cápita considerados como límite de la pobreza, se trata, además, de tener que presenciar, desde puestos de privilegio, como viven los más beneficiados por la falta de equidad y eficacia en la distribución de los recursos. La violencia no podía encontrar un caldo de cultivo mejor que este sostenimiento 
de tan flagrantes ejemplos de insolidaridad y desprecio por la dignidad humana.

En el informe sobre el desarrollo mundial que elabora el Banco Mundial, años 1998/1999, pueden encontrarse multitud de ejemplos de falta de recursos, desprecio por los derechos civiles, mantenimiento de situaciones de desigualdad $o$, simplemente, insolidaridad internacional.

El $68 \%$ de los niños menores de cinco años padecen de malnutrición en Bangladesh; en 1996, un $20 \%$ de los nacidos en Angola no tenían esperanzas de superar los cinco primeros años de vida; la tasa de analfabetismo en Burkina Faso era en 1995 del $71 \%$ en hombres y del $91 \%$ en las mujeres - lo que encierra en sí mismo otro factor de segregación-,... Es difícil saber si la pervivencia de estos dramáticos escenarios es considerada condición sine qua non para perpetuar situaciones privilegiadas de poder. Cuando la luz va abriéndose paso en estos pueblos, y van tomando conciencia de su propia condición, es cuando empieza a ser más probable que los gobernantes caigan en la tentación de tomar en consideración el uso de las fuerzas armadas como última ratio para mantener esta situación. Pero sobre esto se volverá más adelante.

\section{La perversión de las analogías}

El término «aldea global» es frecuentemente usado para referirnos a la interdependencia entre todas las actividades humanas en un mundo, como el actual, en el que la evolución de los transportes ha suprimido la barrera que la distancia creaba entre los seres humanos. Posteriormente, la teoría del caos formuló en términos matemáticos parecidos principios: nada es indiferente a los demás. Pero pocos factores habrán tenido más transcendencia para el desarrollo humano que las comunicaciones. A través de ellas viaja la información, el conocimiento, la cultura en suma. El numero de aparatos informáticos de Eslovaquia es de 186’1 por mil, más que en Bélgica (167’3), Francia (150’7) o España (94'2). Con esta explosión de ordenadores personales no es de extrañar que el número de servidores de Internet por 10.000 habitantes que existen en Eslovenia (85'66) sea superior a los instalados en Japón (75'8) o Italia (36'91); o que Tonga disponga de más servidores (42'6) que España (31), Grecia (18'7) y Portugal (18'2) ${ }^{5}$. Entre los países que disponen de 300 a 400 receptores de TV por cada 1.000 habitantes se encuentran Irlanda, España y Portugal; pero también los Emiratos Arabes Unidos, Eslovenia y Saint Kitts y Nevis ${ }^{6}$. 
Al final, la renta per capita de los PVD se encuentra mucho más alejada de la de los países desarrollados que el idioma, los vaqueros, las hamburguesas o el walkman. En Venezuela, por ejemplo, un autobús es una «traca» ${ }^{7}$ y su depósito de carburante puede estar «full» ${ }^{8}$. Los ciudadanos de estos países aprenden antes lo que es una pagina web que la importancia del ahorro privado para salir de la situación de escasez en la que se encuentran.

Lo que puede observarse, pues, es la imitación de pautas de comportamiento aparentemente inocentes - haciendo abstracción de que la mayoría sean inducidas por potentes y agresivas políticas comerciales-. Pero también es posible observar otras pautas que no lo son tanto, como la deshumanización de la vida que caracteriza a Occidente, la falta de solidaridad, el trabajar para consumir, la comida basura, el alcohol de fin de semana, la ausencia de dialogo o la competitividad salvaje adornada de urbanidad. Con toda seguridad que puede ser discutido, pero cada vez hay más voces que claman por la elección de vías diferenciadas de desarrollo ajenas a las de los países más adelantados o, de otra forma, a la renuncia a un solo camino de acceder a la riqueza y bienestar.

Entre ellas la de Sami Naïr, quien no duda en afirmar que debe replantearse el concepto mismo de desarrollo: «Para las sociedades en transición hacia la economía de mercado, el desarrollo no puede reducirse a la dimensión económica. Su finalidad continúa Naïr - es la integración social global de todas las capas de la población» ${ }^{9}$.

Como muestra de efectos perversos que puede producir la copia de costumbres ajenas a la propia cultura y tradición, baste mencionar el hecho de que el $20 \%$ de los jóvenes chinos (10 millones) padecen de obesidad por imitar la dieta alimentaria de Occidente, reduciendo, al mismo tiempo, el consumo de arroz hervido y verduras.

Como si en una vieja carrocería se instalase un potente motor, la pérdida o deterioro del tejido conectivo propio de las sociedades tradicionales, sin que previamente se haya producido la necesaria socialización de la población, provoca sinergias que dificultan la armónica evolución de los pueblos ${ }^{10}$.

\section{Estabilidad y deuda exterior. Los Gastos de Defensa}

El 16 de marzo de 1999, en una conferencia interministerial entre EE UU y varios países africanos, el presidente Clinton hacía un 
llamamiento para que se condonase la deuda exterior de ese continente, que estaba evaluada en 70.000 millones de dólares. Es una gota de agua en un océano de miles de millones de deuda externa. Por ejemplo, la de Latinoamérica es de 700.000 millones de dólares, diez veces más que la africana, donde solo Ecuador debe 14.300 millones. Un acuerdo al respecto fue alcanzado el pasado mes de junio en la reunión que el G-7 celebró en la ciudad de Colonia.

Entre 1970 y 1995, la deuda externa de los países en vías de desarrollo había pasado de 68.400 millones de dólares a 1,7 billones de dólares ${ }^{11}$. Sólo la deuda que el Norte de Africa tiene con España asciende a 2.500 millones de dólares, siendo la de América del Sur de 1.700 millones.

Si no fuera tan dramático, podría trivializarse con el hecho de que el endeudamiento de algunos de los países más desfavorecidos ha obligado a una nueva catalogación, más ajustada a la realidad, que se incluye en la más general de Tercer Mundo: «Países Pobres Altamente Endeudados» ${ }^{12}$.

En los últimos años se está extendiendo entre los líderes mundiales el convencimiento de que no puede haber estabilidad con depresión. El crecimiento incontrolado de la deuda contribuye, más que cualquier otra cosa, a que la fractura entre el Norte y el Sur se ensanche más de lo soportable. No se trata ya de que las naciones progresen más lentamente de lo que sería deseable en el camino del desarrollo humano; se trata de que la magnitud de la deuda, los conflictos y las catástrofes de todo tipo conducen a la regresión económica y al empeoramiento de las condiciones de vida.

Diversas iniciativas se han adoptado en distintos foros para aliviar esta situación. En la última asamblea anual del Banco Interamericano de Desarrollo las consecuencias de la crisis financiera que se inició en Asia y las del huracán Mitch en las economías de Honduras, Nicaragua, Guatemala y El Salvador, estuvieron muy presentes. Estos cuatro países disfrutarán en los próximos tres años de un aplazamiento en los pagos de la deuda, medida que resulta claramente insuficiente pero que aporta un periodo de reflexión hasta que cuajen iniciativas como las adoptadas por Francia, que ha solicitado a sus socios del G-7 la aplicación de una moratoria de 30 años en el pago de la deuda de los países más pobres.

Es en este escenario donde debe hacerse el estudio del papel que juegan los gastos de defensa. 


\section{El tercer mundo y las Fuerzas Armadas}

\section{Los gastos de defensa y el bienestar}

Mención aparte merece la influencia que los gastos de defensa de las naciones tienen en el volumen de la deuda y el empobrecimiento de los pueblos. Emile Benoit tiene el indiscutible honor de haber sido uno de los promotores de una interesante línea de investigación sobre el papel que los gastos de defensa tienen en el crecimiento de los PVD. Publicados sus estudios en 1973, en un libro titulado «Defensa y crecimiento económico en los países en vías de desarrollo», Benoit afirmaba haber encontrado una estrecha correlación positiva entre gastos militares y crecimiento. Un estudio que abarcaba a 44 países parecía demostrar esta relación entre mayor gasto y tasa de crecimiento.

Las conclusiones de Benoit han tenido variadas respuestas, pero más orientadas a demostrar la falta de esa correlación en otras muestras que la inexactitud de los planteamientos originales. Puede, en resumen, que todavía no se disponga del número de estudios necesario para obtener conclusiones que puedan considerarse definitivas a la hora de averiguar cual es el papel de los gastos de defensa en el bienestar de los pueblos.

En cualquier caso, todo esto no deja de ser una discusión economicista difícil de establecer sin que las ideologías jueguen su papel. Mayor interés tiene analizar el coste de oportunidad de los gastos militares.

Discutido también de forma prolija, un importante grupo de estudiosos ha considerado que los recursos económicos dedicados a mejorar las capacidades defensivas tienen un importante coste, al tratarse de recursos detraídos de actividades que podrían promover importantes modificaciones en la estructura económica y considerables mejoras de la calidad de vida de los ciudadanos.

Los que defienden que los gastos de defensa tienen un coste de oportunidad cero o despreciables, en términos de desarrollo, se apoyanm habitualmente en los siguientes argumentos: a) Dificultad de asignar usos productivos a las inversiones detraídas. La mayor parte de los fondos desviados será empleada en gastos suntuarios, consumo privado, salud o educación, con reducido impacto en el crecimiento económico. b) Dificultad de reasignar fondos anclados al consumo militar. En otras palabras, el retorno de muchas inversiones militares está contractualmente limitado a la industria de armamento. Algunos paquetes de adquisiciones satisfacen en realidad precios políticos, bien para mantener la capacidad de la industria de armamento nacional, sorteando la dependencia exterior en un sector considerado estratégico, bien para promover otras adquisiciones en un mercado sumamente competitivo. 
c) Un tercer argumento se basa en la certeza de que la mayor parte de las adquisiciones que acometieron en el pasado los PVD lo fueron al amparo de programas de ayuda establecidos por las superpotencias durante la guerra fría. En aquellos años, la pertenencia a un determinado bloque y la obediencia a las directrices estratégicas del líder se veían recompensadas con la cooperación en materia de seguridad y la adhesión a programas de adquisiciones en términos muy favorables para los PVD -en algunos casos a coste cero-, al menos en términos de desembolsos dinerarios. Estos créditos, realmente, no eran susceptibles de ser empleados en otras áreas que pudieran responder mejor a las necesidades del momento. d) El último argumento es aquel que considera que los gastos militares en educación, adiestramiento y especialización del personal militar, infraestructura y creación de empleo generan beneficios que se reflejan en mejoras sociales que contribuyen al crecimiento de la nación. En el caso de la educación, porque la industria de armamento requiere una formación en determinadas especialidades - maquinaria de precisión, electrónica, óptica, etcétera-, que puede ser de gran utilidad en la industria civil.

Las críticas se han formulado con la misma o parecida profusión que los argumentos a favor. Más que adiestrar trabajadores en técnicas complejas, la industria militar podría detraer de la industria civil trabajadores muy cualificados y escasos en los PVD. La mayor parte de las adquisiciones que se derivan de programas militares es resuelta mediante importaciones, aun en aquellos recursos que pueden encontrarse en el mercado interior; muchas veces por la propia incapacidad de la industria nacional de estos países para satisfacer con regularidad sus compromisos. Y, por último, invertir en defensa y no en educación sí tiene un coste, ya que invertir en educación es hacerlo en el futuro de la nación. Con relación a este último y particular aspecto, baste recordar que el porcentaje que España dedicó al gasto militar con relación a la suma de gastos en educación y salud fue de un $18 \%$ para los años 1990/91 ${ }^{13}$, uno de los porcentajes más bajos entre los países industrializados. En el mismo período, Israel invirtió un 106 $\%$, la Federación Rusa un $132 \%$ y Albania un $51 \%$.

Como ya ha sido apuntado, puede que los estudios de Benoit se realizasen en un período en el cual la ayuda exterior en programas militares tenía un considerable impacto, cubriendo la mayor parte de las necesidades que se derivaron de los programas de inversión. Puede también que todavía estemos lejos de obtener resultados indiscutibles sobre la influencia de los gastos de defensa en la tasa de crecimiento económico de los PVD; pero todo este debate no resuelve más que los 


\section{El tercer mundo y las Fuerzas Armadas}

efectos económicos que se derivan de las inversiones realizadas. Con mucha frecuencia, en general, y casi siempre en los PVD, la cuestión no radica en averiguar el volumen de ingresos o gastos ligados a los programas de armamento, sino si hay alternativa para ellos; de otra manera, no es tan importante averiguar si estos gastos tienen un coste como saber si estos países disfrutan de otras oportunidades reales de inversión.

En el Cuadro 1 se han analizado tres grupos de 15 países cada uno de ellos: los de la OTAN antes de la ampliación; los 15 más pobres, o con Indice de Desarrollo Humano más bajo según el Programa de la Naciones Unidas para el Desarrollo (PNUD); y un tercer grupo de otros 15, en este caso, escogidos entre aquellos que viven un conflicto histórico, de los que hunden sus raíces casi en el origen de los tiempos. Se ha evitado conscientemente la elección de países con crisis coyunturales, por muy graves que éstas pudieran ser; de menor interés cuando se desea, por el contrario, analizar rasgos económicos de naciones con dificultades larvadas que de vez en cuando, y varias veces en el siglo, saltan a las primeras páginas de los periódicos. Se trata, en suma, de intentar descubrir la influencia que la inseguridad como percepción tiene en las cuentas estatales.

La columna (c) representa el porcentaje de ciudadanos sirviendo en las Fuerzas Armadas (b) sobre el total de la población (a), medido en tantos por mil. Es un índice de «aseguramiento» y refleja la importancia que se le da a la defensa de los intereses nacionales. Sorprende comprobar que la media de los 15 países inmersos en conflictos duraderos es cinco veces la de los 15 más pobres, y dobla la media de las 15 naciones de la Alianza Atlántica. Los efectos de detraer tal proporción de mano de obra, algunas veces muy cualificada, tienen que tener su registro en las cuentas nacionales.

La columna (d) refleja la cuota de los gastos de defensa en el PIB expresada en tantos por cien. Otra vez, la media de los 15 países con un entorno de seguridad deficiente dobla la de la OTAN y la de los países con menor HDI.

Con ser representativos, ninguno de estos índices produce el impacto de los registrados en la columna (e). De acuerdo con los datos calculados, la defensa le cuesta como media a los ciudadanos del grupo de PVD amenazados 75 veces más que a los de menor HDI, y prácticamente igual que los 488 dólares - 215 a los españoles - que le cuesta la defensa a los ciudadanos de países miembros de la OTAN, sin comparación posible al tratarse en general de los más ricos.

A pesar de su potencia económica, EE UU — con 1.000 dólares per cápita- sería superado por Kuwait (2.218 dólares), Arabia Saudita 


\section{Juan Carlos Domingo Guerra}

CUADRO 1

\begin{tabular}{|l|c|c|c|c|c|}
\hline & $\begin{array}{c}\text { POBLACIÓN } \\
\text { (a) }\end{array}$ & $\begin{array}{c}\text { FF AA } \\
\text { (b) }\end{array}$ & $\begin{array}{c}\text { FF AA } \\
\text { POBLACION } \\
(\%) \\
\text { (c) }\end{array}$ & $\begin{array}{c}\text { GASTOS DE } \\
\text { DEFENSA } \\
\text { (cuota en PIB) } \\
\text { (d) }\end{array}$ & $\begin{array}{c}\text { GASTOS DE } \\
\text { DEFENSA } \\
\text { (US \$ p.c.) } \\
\text { (e) }\end{array}$ \\
\hline $\begin{array}{l}\text { I Grupo: } 15 \\
\text { PVD con } \\
\text { menor HDI } 14\end{array}$ & 390.107 .074 & 562.500 & 2,16 & 3,09 & 5,47 \\
\hline $\begin{array}{l}\text { II Grupo: } 15 \\
\text { PVD amena- } \\
\text { zados 15 }\end{array}$ & 1.485 .044 .906 & 4.967 .800 & 10,16 & 5,81 & 409,20 \\
\hline $\begin{array}{l}\text { III Grupo: } 15 \\
\text { Países } \\
\text { OTAN } 16\end{array}$ & 712.518 .817 & 3.990 .000 & 5,83 & 2,44 & 488,20 \\
\hline
\end{tabular}

Los datos necesarios para elaborar las columnas (a), (d) y (e) se sacaron del Atlas Mundial Microsoft Encarta, edición de 1997. Los datos para la columna (b) se extrajeron del Informe sobre Desarrollo Humano, PNUD, 1998, con excepción de los correspondientes a Ruanda (33.000 hombres), que se obtuvieron en «El Estado del Mundo", edición de 1998, Anuario Económico y Geopolítico Mundial, Editorial AKAL. La información de la columna (a) es de 1997; la de las columnas (d) y (e), de 1996. Las columnas (c), (d) y (e) representan medias.

(1.030) o Israel (1.624). Hay que precisar, no obstante, que la interpretación correcta de las columnas «Gastos de Defensa. Cuota en el PIB» y «Defensa. Gastos per Cápita», exigiría conocer la proporción de la partida de defensa que va a personal y a material - salarios y sostenimiento e inversiones-. Un gasto del $100 \%$ en personal, por ejemplo, no significaría mucho más allá que un uso de las $\mathrm{FF}$ AA como empleador público y un considerable derroche de recursos. Un índice de seguridad elevado — columna (c) - podría significar también inestabilidad interior o militarización de la sociedad. Ambos análisis trascienden del objetivo de este trabajo, pero parece que los números expuestos reflejan el esfuerzo que, en términos económicos, un entorno de inseguridad impone a los PVD, al detraer recursos de otros sectores con un mayor impacto en la calidad de vida los ciudadanos.

La elaboración de los cuadros parciales que corresponden a cada grupo de países permitió vislumbrar la ausencia de una relación inequívoca entre sistema político y beligerancia. No parece, con otras palabras, que sean más pacíficas las democracias, ni más violentos los autoritarismos; algunas veces incluso, tampoco significa demasiado sobre las garantías previas a una intervención. 


\section{El tercer mundo y las Fuerzas Armadas}

Con relación a la influencia que la carrera de armamentos ha tenido y tiene en la mayor o menor probabilidad de que un contencioso acabe en guerra o conflicto armado, debe ser subrayada la debilidad de los argumentos que defienden tal relación. En cualquier caso que se analice, siempre cabrá la duda de si la guerra fue una consecuencia del rearme o éste una necesidad para acometer aquella con ciertas garantías de éxito.

Los hechos que se deducen del Cuadro 1 parecen demostrar que la proliferación de armamentos se deriva más de la percepción de una amenaza para la propia seguridad (real o figurada) —o de la pervivencia de soluciones percibidas como injustas que fueron adoptadas en un tiempo en el que se carecía de peso internacional para hacer valer los propios argumentos-, que de una decisión libremente adoptada por adquirir bienes que se reconocen como ajenos.

La discusión sobre los costes de oportunidad, pues, se nos aparece como intranscendente cuando tal oportunidad es sólo académica o no existe, sin más. ¿Qué margen deja la seguridad? ¿Cuál es el abanico de alternativas cuando el entorno no es seguro? Arora y Bayoumi ${ }^{17}$ reconocen este factor como marco dentro del cual dèberían interpretarse sus conclusiones con relación a los beneficios que, para la economía, tendrían los recortes en el gasto militar. En general, y también aquí, sus trabajos se centran en estudiar los beneficios económicos «pero reconociendo la necesidad de sopesarlos con cualquier impacto que los recortes en el gasto tengan en la seguridad nacional». Estos economistas llegan a la conclusión, en sus investigaciones para el FMI, de que una reducción concertada de todos los países en gastos de defensa produce mayores beneficios en cada economía que los obtenidos al disminuir unilateralmente los gastos de uno de ellos. Las razones - siguen los autores- pueden encontrarse en la reducción generalizada de los tipos de interés y en el incremento del comercio mundial que se induce al sustituir el componente de gastos militares por el superior de los gastos del sector privado que los reemplaza.

En realidad, pocas dudas hay de la conveniencia de mantener una adecuada proporción coste-eficacia de los gastos militares. La proliferación de cabezas nucleares de las superpotencias con capacidad para destruir varias veces nuestra civilización, además de una muestra de la estupidez humana, lo es del derroche de recursos escasos tan necesarios en otros lugares.

Pero no es tan sencillo materializar iniciativas tan obvias, por otra parte, ni determinar a partir de que nivel de reducción en términos presupuestarios aparecen desequilibrios defensivos, ni el papel que ju- 


\section{Juan Carlos Domingo Guerra}

garía la mayor o menor eficiencia de los gestores de las partidas dedicadas al gasto de armamento. La gran interrogante vendría constituida por la incertidumbre de cuando, en un hipotético escenario de reducciones armonizadas, se sobrepasaría aquel nivel en el que una agresión podría iniciarse con pocos o asumibles riesgos, esto es, donde estaría el umbral de la indefensión en los gastos militares.

En definitiva, es fácil apoyar propuestas como las de Arora y Bayoumi, pero alcanzar un entorno mundial de mayor seguridad es el papel de las Naciones Unidas, y ya se sabe cual ha sido, hasta ahora, el resultado. Quizás el futuro esté en satisfacer la necesidad de avanzar en la creación de medidas de confianza o garantías de seguridad supranacionales creíbles, siempre que se pueda asegurar que los intereses de la nación líder, o de aquellas que más aporten al entorno de seguridad, no se transformen en una carga insoportable para los más necesitados. Estamos hablando de un mundo nuevo, basado en otros principios que, por desgracia, hoy todavía están lejos de regular las relaciones humanas.

\section{Las Fuerzas Armadas en los Países en Vías de Desarrollo}

\section{El papel de los militares}

«Parece que las instituciones militares pueden tener un papel modernizador en las economías de los países de bajo nivel de desarrollo - afirma Saadet Deger ${ }^{18}$ _, pudiendo contribuir a cambios estructurales. Este tipo de dinámicas institucionales debería estimular el crecimiento en cierto sentido». Esta afirmación ayuda a introducir un tema polémico: el de la contribución de los militares a sus respectivas sociedades.

$\mathrm{Y}$ es que Saadet Deger no pretendía hacer una defensa de los militares como comunidad sino, muy al contrario, salir al paso de las conocidas teorías de Emile Benoit ${ }^{19}$ quien, en sus trabajos sobre la influencia de los gastos de defensa en el crecimiento de los países en vías de desarrollo ya mencionados, defendía los beneficiosos efectos que podían ser atribuidos a la defensa. De los dos factores que constriñen el crecimiento - dice Deger-, el papel de la modernización y la ausencia de ahorro doméstico, la institución militar puede tener sólo beneficiosos efectos en el primero ${ }^{20}$. 


\section{El tercer mundo y las Fuerzas Armadas}

Con independencia de lo atractiva que pueda resultar esta discusión, lo cierto es que se merece el calificativo de espuria. No tiene más valor profundizar en la contribución de los militares a sus respectivas sociedades que el que pueda extraerse del mismo esfuerzo volcado en los arquitectos o empleados de Bolsa; todos ellos ejercen actividades para las que se ha formulado una demanda social, con independencia de cuales hayan sido los mecanismos empleados para ello. Pero, aunque sólo sea como ejercicio intelectual, merece la pena terciar para recordar que Benoit adjudicaba potencialidades de desarrollo a la institución castrense en los PVD y no así en los países industrializados, para los que consideraba que jugaba en contra de este papel el supuesto arcaísmo de la institución y las ataduras que significan las tradiciones.

Sin embargo, ya sea porque en el campo de la seguridad y defensa nada se basa exclusivamente en la superioridad de los recursos materiales, sino en las convicciones ${ }^{21}$, ya sea porque este campo del saber tiene tanto de ciencia como de arte, y la imaginación y creatividad están siempre presentes en este último, lo cierto es que también en los países industrializados la actividad que los militares desarrollan produce beneficios que trascienden más allá del exclusivo campo de la defensa. Como ejemplos, debería bastar con citar el hecho conocido de que Internet tiene sus antecedentes en un proyecto del Pentágono estadounidense; que algunos sistemas de optimización de decisiones empresariales tienen sus orígenes en la resolución de problemas estratégicos, durante la II GM; o que, mucho más cercano en el espacio, las actuales ingenierías civiles en España tienen sus orígenes en 1726, con el establecimiento en el Alcázar de Segovia del Colegio de Artillería del Ejército; en 1739, con la creación, en Barcelona, de la Academia General de Matemáticas, donde se formaban los artilleros e ingenieros militares; y en 1772, cuando Carlos III crea la Academia de Ingenieros de la Armada ${ }^{22}$.

Abundando en ejemplos de la influencia que en otros ámbitos tiene la función defensa, puede añadirse que la adhesión de España al Tratado de No Proliferación de Armas Nucleares, por ejemplo, y a todos aquellos convenios que remiten a instancias supranacionales el arbitraje en los conflictos, así como la renuncia a disponer de una fuerza militar disuasoria en términos convencionales, son todos ellos hechos que han aumentado la consideración de España como mediador en litigios internacionales y demostrado hasta la saciedad el espíritu de concordia de los españoles. Pero sería de ingenuos no reconocer su adversa influencia en la resolución de conflictos como el del Sahara y el del fletan, en la mejor defensa de los intereses españoles en el contencioso 
de Gibraltar, en la asignación de un asiento permanente en el Consejo de Seguridad de las Naciones Unidas o en la inclusión en el Grupo de Contacto que negocia con las partes en Bosnia-Herzegovina.

Pero pidiendo disculpas por la digresión y regresando al mundo en desarrollo, como en casi todo las ideologías juegan aquí un importante papel. Lo que para algunos puede ser una contribución neta: la creación de puestos de trabajo que exigen la adquisición de una formación especializada y la formación de trabajadores con una elevada cualificación (Deger, Benoit); para otros (Todaro ${ }^{23}$ ) puede significar tener que enfrentarse, además, al drenaje de trabajadores muy cualificados de la industria civil. Haciendo abstracción de unos y otros, parece suficientemente justificado el interés que tiene aproximarse al papel que lo militar juega en muchos de los PVD.

Con la dificultad de establecer características que sean compartidas al mismo tiempo por los miembros de la Fuerza Aérea de Argentina y por los del Ejército de Etiopía, por citar sólo algunos, es relativamente sencillo descubrir en ambos grupos técnicas de trabajo organizado, renuncia a lo individual en beneficio del trabajo en equipo, extensión y cultivo de valores colectivos o el mero desarrollo de avanzadas técnicas de gestión de recursos humanos. La disciplina, austeridad y renuncia a otras ventajas asociadas a la estabilidad de residencia - vivienda, educación de los miembros de la unidad familiar, integración en la comunidad- son también habituales en los miembros de estos ejércitos. Con las excepciones que posteriormente serán comentadas, aquellos que optan por servir a sus países en el seno de las fuerzas armadas renuncian de antemano, y con un considerable derroche de generosidad, al ejercicio pleno de derechos civiles o a la intervención directa en la negociación de aspectos laborales que atañen directamente a su calidad de vida. Y esto, sorprendentemente o no, es también común a la mayor parte de sus colegas de la Alianza Atlántica.

\section{Los sentimientos}

Con la excepción de los regímenes comunistas asiáticos, en los que los procesos revolucionarios se asentaron en llamamientos a soldados y trabajadores que, con el tiempo, provocarían la consolidación de una sociedad civil «uniformada», las FFAA de los PVD se caracterizan por tener un acusado sentido patrimonial del concepto de patria, que resumen en el conjunto de aquellas características de la nación y su 


\section{El tercer mundo y las Fuerzas Armadas}

experiencia colectiva que proporcionan a los ciudadanos aspectos tangibles de su conciencia de pertenecer a una comunidad diferenciada. En la senda del desarrollo, la idea de patria es objeto de un proceso de sacralización que acaba dotándola de aspectos mágicos, más acentuados cuanto más primitiva sea la sociedad sobre la que se asienta la nación. La patria se percibe con carácter excluyente. Los miembros de las FFAA no comparten los mismo ideales que el resto de la sociedad, donde los ciudadanos están más volcados en la consecución de sustanciales mejoras de sus condiciones de vida. La apelación a los hechos de los fundadores o padres de la patria, en la historia de cada pueblo, es constante y, normalmente, subraya aspectos sobrenaturales o sobrehumanos de su biografía ${ }^{24}$. Los miembros de estos ejércitos no se consideran solamente como depositarios de valores transcendentales sino que, además, tienden a considerarse los únicos legítimamente acreditados para custodiarlos. Estos esquemas contribuyen a establecer una brecha entre la sociedad y sus militares, creando condiciones óptimas para que ambos grupos humanos pervivan y se desarrollen diferenciados.

La conciencia nacional evoluciona primando consideraciones diferenciales con relación a sus propias sociedades civiles, primero, y con relación a los demás, después. La idea de ser antagónica tiene en sí misma el germen de los conflictos. Se es sólo frente a otros más que con otros, y la existencia de enemigos, reales o imaginarios, se convierte en un claro instrumento de reafirmación nacional. En esta búsqueda de antagonismos se trataría de encontrar la raya de hasta donde podemos llegar o hasta donde nos van a permitir los otros que lleguemos. El suelo se convierte así en un factor de reafirmación de primer orden, y las fronteras en su materialización. Los conflictos basados en reclamaciones territoriales y en el irredentismo de estas reclamaciones tienen la virtud de tocar las fibras más sensibles de la nacionalidad, lo que los hace idóneos para su manipulación como forma de sofocar o encubrir descontentos internos al desviar la atención de los ciudadanos de otros problemas domésticos ${ }^{25}$. En aquellos procesos de búsqueda de la propia identidad, el suelo es algo más que el territorio en el cual se ejerce la soberanía, todo lo contrario de lo que parece estar sucediendo en los países más desarrollados; en estos, y sobre todo en Europa, los tratados de Schengen y Maastricht parecen indicar un proceso inverso: las naciones se ven en general inmersas en la búsqueda de novedosos espacios de cooperación que están modificando, en un grado que hubiera sido difícil de imaginar hace tan solo unos años, incluso la geografía física de las naciones. 
Sin embargo, y desde una perspectiva histórica, pocos litigios pueden ser más artificiosos que los disputados por las demarcaciones territoriales. Basta echar un vistazo al mapa político de Africa o al de la península Arábiga. El ocaso de los imperios coloniales a mediados del siglo XX trajo consigo el nacimiento de nuevas entidades estatales no siempre basado en un previo reconocimiento de anhelos autonómicos. Criterios geopolíticos - la búsqueda de equilibrios regionales o la conveniencia de mantener altas cotas de influencia-, y el deseo de lavar la mala conciencia de las potencias occidentales - al finalizar la II Guerra Mundial-, se encuentran también entre los orígenes de algunos reconocimientos de independencia ${ }^{26}$. Pero es que, además, las fronteras que hoy conocemos tienen poco que ver con las que existían hace un siglo, por citar una fecha, lo que desmiente el carácter cuasi sagrado de las mismas.

Aunque deseásemos observar el mundo actual desde la perspectiva del desarrollo, lo cierto es que en las postrimerías del siglo XX bien puede decirse que éste se ha ganado el calificativo de "siglo de la violencia». Con independencia de cuales hubiesen podido ser nuestros deseos, lo cierto es que las fuerzas armadas son todavía instituciones necesarias para garantizar la supervivencia como nación de muchas entidades estatales ${ }^{27}$. En los países desarrollados los ejércitos constituyen un instrumento de primer orden de su política exterior y un argumento de peso en las negociaciones internacionales. Países como los Estados Unidos de América, que disponen de armamento almacenado como para destruir varias veces el mundo conocido, todavía consideran que la contribución de los aliados a la resolución de conflictos con soldados es el signo más claro de la voluntad de cooperar y de la vocación de significar algo en el concierto internacional. Consecuencia de la importancia que el cuerpo electoral tiene en los países democráticos, el impacto adverso en la opinión pública de una posible repatriación de cadáveres es un riesgo que pocos líderes mundiales quieren correr en solitario.

Volviendo a esto más adelante, en muchos países del Tercer Mundo, sin grandes recursos o interés estratégico que les garanticen la asistencia de primeras potencias en el campo de la seguridad, sus unidades militares constituyen su única garantía de supervivencia. En otros, sin embargo, prevalecen razones de política interna, y es la autoridad nacional la que ha buscado su apoyo o está asentada en las fuerzas armadas o en parte de ellas. Los ejércitos se convierten así, consciente o inconscientemente, en instrumento político de primer orden y argumento de represión interna. Su función primigenia se subvierte y los efectos de esta subversión de valores son devastadores para la propia 


\section{El tercer mundo y las Fuerzas Armadas}

institución. Con el paso del tiempo, la búsqueda de aliados es sustituida por la del enemigo, que no puede ser otro que el propio del dictador y de la opción política que representa o que le sustenta. El uso perverso de las unidades militares convierte a éstas en represoras de las libertades de su propio pueblo. La función policial que desarrollan aparta a sus oficiales y suboficiales del interés por específicos temas de defensa y por el conocimiento de su evolución en otros países.

Estas fuerzas armadas, en resumen, se ven en general abocadas a trocar discutibles privilegios de algunos de sus miembros por la animadversión de sus pueblos, llevando en sí mismas el germen de su descrédito y autodestrucción.

\section{El intervencionismo militar}

La aproximación a la teoría del intervencionismo militar en todo el mundo ha sido siempre de difícil materialización. En mayor o menor grado, la cuestión militar ha estado presente en la reciente historia de la mayor parte de los países que constituyen la sociedad de naciones. La historia del golpismo o intervención militar violenta en los asuntos de gobierno está repleta de cualquier clase de ejemplo que quiera buscarse. Con independencia del rigor de identificar como progresistas movimientos castrenses anteriores al siglo XIX, lo cierto es que durante las últimas décadas de la historia del ser humano ha habido movimientos que supusieron retrocesos y avances en las libertades de los pueblos. Hubo, también, pasividades o apoliticismos - como en la Wehrmacht de los años treinta - que fueron reputados por analistas como indiferencias culpables ante acontecimientos de tremenda importancia para el futuro de Europa ${ }^{28}$.

Diego Azqueta ${ }^{29}$ busca los orígenes del intervencionismo militar en el Tercer Mundo en la ausencia de una clase burguesa y capitalista. Ese hueco sería ocupado por el Ejército, institución que se define como moderna y nacionalista avanzada, cualidades que lo hacían idóneo para dirigir el proceso de industrialización del país y que contaría con «la aprobación de una parte de la intelectualidad de izquierdas» ${ }^{30}$. La experiencia - concluye Azqueta- resultó poco edificante, aunque se reconozca que en estos países los ejércitos son, quitando a empresas multinacionales allí instaladas, de las pocas instituciones disciplinadas y jerarquizadas, con cotas de eficacia similares a otros estándares y que, además, son capaces de proporcionar cuadros de mando a la administración. 
La circunstancia de que las fuerzas armadas materializan la opción más destacada de una de las atribuciones del Estado: el monopolio de la coacción física legítima ${ }^{31}$, no debería hacernos dudar sobre lo inconveniente de dejar a la interpretación de los militares el decidir en que situaciones estaría justificada la intervención. El poder de que se dota a las unidades militares tiene que ser empleado en aquello que está previsto en las respectivas Constituciones, y los ciudadanos de uniforme deben asumir que su único cauce de intervención en los asuntos públicos pasa por las urnas en las distintas convocatorias electorales. Esto es siempre verdad y debe mantenerse aun en aquellos casos en los que la actuación de los ejércitos coincidió con los deseos de la mayoría, recibiendo el aplauso del público ${ }^{32}$. Lo contrario abre la vía del intervencionismo al dejar al criterio de los actores la valoración de la gravedad de la situación que justificaría la intermediación militar.

En cualquier caso, falta todavía por acometer un análisis profundo sobre la irresponsabilidad de los líderes políticos que apelan al arbitraje de sus fuerzas armadas para dirimir disputas entre partidos. Al igual que en el squash, la pelota tarde o temprano adoptará una trayectoria inesperada, sorprendiendo a todos los jugadores. Esta perturbación de la normalidad institucional produce algunos efectos anómalos que coexisten con prácticas democráticas de dudosa ortodoxia, como la ambigüedad de los apoyos con los que cuentan determinadas candidaturas, o la apelación al sentido cívico del electorado por el procedimiento de apercibirle de las indeseables consecuencias que tendría el triunfo de determinadas opciones políticas. Encontramos buenos ejemplos en las elecciones venezolanas de 1999, o en la forma en la que Boris Yeltsin resolvió, en mayo del mismo año, la crisis gubernamental ${ }^{33}$.

Pero es que, como se comentaba antes, y a falta de otros análisis, el efecto del intervencionismo es tanto o más perverso en el seno de las mismas fuerzas armadas que, convertidas en árbitros de la actividad política de su país y concentradas en asuntos domésticos, acaban desatendiendo funciones básicas de la defensa. Transmutados en figuras relevantes de la vida política del Estado, los representantes de las fuerzas armadas acaban tomando parte activa al promover el apoyo de las unidades militares a distintas opciones políticas. La apuesta por el poder es, en estos casos, sólo cuestión de tiempo; la existencia de disensiones en el seno de las fuerzas armadas conducirá a la guerra civil en la mayor parte de ellos.

Especial consideración merece la influencia que en el desarrollo de estas sociedades civiles tienen los regímenes autoritarios. Frente 


\section{El tercer mundo y las Fuerzas Armadas}

a mejoras sectoriales derivadas de la corrección quirúrgica de los males que justificaron la intervención militar en la vida pública, aparece una clase empresarial especializada en acometer negocios al amparo de políticas proteccionistas asociadas a concepciones autárquicas de la actividad económica. La falta de competencia, los subsidios, la intervención con criterios políticos en las actividades de exportación e importación - lejos de los criterios habituales de mercado-, son factores que adormecen la imaginación de los agentes económicos y su espíritu de iniciativa al disuadirlos de buscar oportunidades de negocio con el riesgo que supone acometer nuevas empresas, características, todas ellas, de una clase empresarial capaz de crear puestos de trabajo y contribuir a la riqueza nacional. Con el paso del tiempo, la seguridad de los beneficios y la dificultad de modificar los marcos estructurales hacen que los profesionales más cualificados busquen fuera de su país el ambiente que les permita su desarrollo en plenitud. Ya sea por apatía, ya por asfixia, en estas sociedades el capital humano está abocado a agostarse en el temor al poder, la rutina y la falta de oportunidades.

No es el descrédito en la comunidad internacional otro aspecto desdeñable ${ }^{34}$. Las dificultades para invertir en espacios políticos inseguros o con mercados excesivamente intervenidos se contrapone a las facilidades que encuentran grandes capitales. Algunas multinacionales petroleras en Oriente Próximo u hortofrutícolas en el continente americano no pueden eludir las sospechas de cooperar, en pos del mantenimiento de cuotas privilegiadas de mercado, al sostenimiento de regímenes establecidos por la fuerza de las armas o poco respetuosos con los derechos humanos. Algunas prácticas de la comunidad internacional, como los embargos, la prohibición de exportación de materias primas o importación de determinados productos necesarios en la industria civil, tienen efectos discutibles en los objetivos que se pretenden alcanzar, aumentando, sin embargo, el sufrimiento de la población en general ${ }^{35}$.

Algunos aspectos del espacio único jurídico internacional, que puede deducirse de recientes providencias judiciales, permiten aventurar un futuro en el que cada vez sean más arriesgadas las conductas antisociales y el disfrute de beneficios obtenidos de la corrupción y el poder ilegítimamente adquirido.

\section{El Papel de las Otras Fuerzas Armadas}

El soporte de cualquier programa de cooperación es el entendimiento. La influencia se crece en la comprensión y el respeto a otras tradiciones, 
costumbres y, en resumen, códigos de valores. Hay que conocer antes de apoyar, como único procedimiento para que la ayuda contribuya a un efectivo desarrollo de las capacidades. Algunos esfuerzos por mejorar las organizaciones defensivas del Tercer Mundo han visto fracasar las iniciativas volcadas en la educación y el adiestramiento y cómo sobrevivían, por el contrario, exclusivamente las materializadas en programas de adquisición de armamentos y otros productos finales. Las becas concedidas hace unos años, por citar un ejemplo, para financiar el paso de oficiales guineanos por centros de formación de las fuerzas armadas españolas eran asignadas, en aquel país, a oficiales que ya habían cursado estudios en otros centros del extranjero, principalmente en la antigua URSS, desperdiciándose la oportunidad de extender los privilegios de una buena educación a círculos fuera del poder y contribuir así a la expansión de principios habituales en las fuerzas armadas occidentales.

Los responsables de los programas de cooperación tienen que modificar drásticamente la perspectiva desde la que se aproximan a las sociedades con las que van a cooperar, y éste se revela como un problema a veces insuperable. Qué códigos usar, o qué valores defender y hasta qué punto, son preguntas que habitualmente se hacen los cooperantes. Sin posibilidad de promover la aceptación de formulas magistrales, lo razonable es el respeto más absoluto por las peculiaridades de otras culturas que no afecten a códigos propios de conducta que consideremos básicos y fundamentales ${ }^{36}$. Se trata de separar lo anecdótico de la promoción de aquellos valores que deberían justificar la cooperación en temas de defensa. Esto, que parece sencillo de formular, encierra un consejo a jóvenes oficiales destacados en países del Tercer Mundo para que huyan de expresiones de rechazo por costumbres locales intrascendentes y tan razonables -o irracionales - como las propias; y a las naciones para que disminuyan, sino prescindan, de la hipocresía o exceso de pragmatismo que normalmente preside las relaciones internacionales. Sólo desde esta hipocresía es posible entender las razones de la intervención internacional -incluso de la ONU- en conflictos cercanos mientras se producen miles de muertos en otros - como en la República Democrática del Congo (antes Zaire) y Somalia- que, salvo circunstancialmente, han permanecido ausentes de los noticiarios de la $\mathrm{CNN}^{37}$. La Escuela de las Américas que el ejército de los $\mathrm{EE}$ UU tenía instalada en Panamá puede ser, por los líderes que pasaron por sus aulas y el papel jugado en la historia de sus pueblos, un claro ejemplo de la ambigüedad en los objetivos mostrada por algunos programas de cooperación. 


\section{El tercer mundo y las Fuerzas Armadas}

En 1980, un coronel de las fuerzas armadas españolas acompañaba a otro de un país latinoamericano, de visita en España. En determinado momento, nuestro visitante preguntó a su anfitrión español por las razones de que el vehículo oficial, en el que viajaban, se detuviese en los semáforos. Extrañado por la pregunta, el español se interesó por la razón de su sorpresa: «Nosotros no lo hacemos - contestó-, porque la autoridad que no abusa se desprestigia».

Uno ha oído suficientes veces anécdotas parecidas como para dudar de la originalidad de su autor, que no del narrador, pero es suficientemente ilustrativa de una forma de entender lo militar en algunos países. En sociedades de muy bajo nivel de desarrollo o estructuras civiles muy elementales, los miembros de instituciones estatales, y entre ellas los de las fuerzas armadas, pueden tener la tentación de considerarse parte de los círculos de poder; en otras palabras, de considerarse titulares legítimos del derecho a ejercer la violencia sobre sus conciudadanos. Estas actitudes, sin los límites que impone el respeto a las normas de un estado de derecho, explicarían la intervención de unidades regulares en matanzas como las que tuvieron lugar en Ruanda y Zaire en 1997.

Pero quizás una de las diferencias más sorprendentes entre los miembros de las fuerzas armadas de países desarrollados o en vías de desarrollo es, contra todo pronóstico, el peso específico que la vocación tiene en la elección de esta forma de vida. En el acervo cultural de los militares y de la sociedad a la que pertenecen, y en el ámbito de la formación institucional que se imparte en los centros de formación, se trataría de aclarar la cuestión de si la permanencia en los ejércitos supone el ejercicio de una determinada profesión o la opción libre por prestar un determinado servicio.

En los PVD el carácter vocacional prevalece entre sus miembros, incluyéndose aquí también aquellos casos en los que la posibilidad de disfrutar de una determinada situación de privilegio o superioridad con relación el resto de la población deforme el carácter de aquél. Las fuerzas armadas son, aquí, el principal elemento de cohesión nacional y se perciben como la razón última de la existencia como nación. En los países desarrollados, por el contrario, aparece muy destacado el carácter ocupacional de la relación de servicios profesionales que mantienen con las fuerzas armadas sus miembros. La oferta de plazas a cubrir en los ejércitos profesionales tiene que competir en el mercado laboral en las mismas condiciones que el resto del empleo público y aun privado y, lo que tiene más importancia, con sus mismos argumentos: estabilidad laboral, salarios adecuados, prestigio social, etcétera ${ }^{38}$. En 
un ejército occidental sus profesionales están más dispuestos a aceptar una gran variedad de misiones en defensa de intereses nacionales, sin cuestionarse su legalidad, que hacen descansar en las garantías que ofrecen sus sistemas parlamentarios. Sienten, estos profesionales, que su disponibilidad es parte de lo que se espera de ellos y la razón que justifica la retribución de sus servicios, con independencia de que vaya acompañada por el imprescindible aprecio del resto de la sociedad a su función. En Occidente, las fuerzas armadas son un indispensable instrumento de política exterior que se dota porque se considera bastante probable su empleo, obteniendo el beneficio esperado de una inversión realizada vía presupuestos. Los soldados de un ejército profesional asumen las incomodidades que lleva consigo su adiestramiento porque, tarde o temprano, su supervivencia dependerá de ello. En definitiva, los gastos de defensa son considerados una inversión de la que se espera obtener los rendimientos propios de un bien público - ya sea en defensa de intereses directos, ya en términos de percepción de un mayor nivel de seguridad-.

El resultado es un profesional que, como el resto de sus conciudadanos, ha desvestido a su actividad principal del carácter heroico que todavía subsiste, atribuido en exclusividad a los militares, en sociedades de países menos desarrollados. Por el contrario, desde las fuerzas armadas de estos países, los modelos occidentales adolecen de exceso de espíritu funcionarial en detrimento, supuestamente, de valores que han venido siendo considerados como inherentes al ser militar. Se plantea, en resumen, una artificiosa necesidad de elegir entre ciudadano y guerrero, funcionario o héroe.

La falta de atractivo del modelo occidental, por lo apuntado, es un efecto que debe ser compensado, y no debería ser muy difícil hacerlo, con éxito. La eficiencia de los modelos basados no solamente en la superioridad técnica, sino también en la bondad de los sistemas de adiestramiento y procedimientos científicos contrastados, debe ser convenientemente presentada junto con el respeto por el mantenimiento de valores tradicionales, indiscutiblemente necesarios a los hombres que deban arriesgar sus vidas por razones tan pedestres como garantizar la continuidad en el abastecimiento de recursos petrolíferos o el mantenimiento del comercio a través del canal de Panamá -y consiguiente abaratamiento de los precios de los transportes-. Más aun, parece que es en estos casos donde son más necesarios hombres con una sólida formación y que estén dispuestos a correr riesgos considerables en defensa de intereses legítimos de su nación, aunque no los perciban como cercanos. Es suficientemente ilustrativo subrayar 
que, como se ha observado en los últimos conflictos, los soldados del ejército de los EE UU cumplen las misiones que les son encomendadas, por los más variados motivos y en cualquier parte del mundo, suficientemente armados con la convicción moral de estar haciéndolo por su país, por muy genérica que pueda parecer esta convicción.

En cualquier caso, es bueno que se superen los recelos e indiferencias mutuos. En algunas ocasiones, con motivo de reuniones internacionales, se cae en la tentación de observar a colegas a través del prejuicio que se deriva del sistema político que rige el destino de su país. En las organizaciones defensivas multilaterales, esto puede llegar a convertir a los oficiales que proceden de PVD en personas no gratas o parias de la organización, lo que producirá pérdida de valiosas contribuciones personales y resquemores que, en el futuro, pudieran traducirse en obstáculos a la cooperación.

Difícil de resolver es el impacto que en los PVD en general y en sus fuerzas armadas, en particular, tiene la extendida práctica de vetar el ingreso en organizaciones defensivas multinacionales de aquellos países que son regidos por regímenes predemocráticos o en los que no se respeten suficientemente los derechos humanos. La defensa colectiva tiene sus inconvenientes, como atender a los compromisos contraídos, pero también la ventaja de optimizar la relación coste-eficacia del esfuerzo presupuestario en defensa. El nivel de seguridad que se alcanza a través de sistemas colectivos es infinitamente superior al que podría obtenerse en solitario. Esto es verdad para un país como EE UU, donde, posiblemente, organizaciones como la OTAN ofrecen, en primer lugar, un foro de consultas y un espacio para alcanzar el deseable grado de consenso cuando han de adoptarse decisiones políticas consideradas de alto riesgo.

Para los PVD, la asimetría de las formas de gobierno que llevan consigo falta de aceptación de la comunidad internacional se traducirá en mayores costes - los que requiere una defensa unilateral- y una mayor dependencia, con contadas excepciones, de proveedores externos de armamento. La principal consecuencia de esta dependencia es la inseguridad de las corrientes de abastecimiento, inseguridad que puede llegar a ser dramática si se confirma en plena crisis. Durante la guerra de las Malvinas, Francia - proveedora del EXOCET - dejó de suministrar este eficacísimo misil aire-superficie justo en el momento en que más necesario era para la reposición de los consumidos por la fuerza aérea argentina, con resultados ya conocidos. 


\section{La cooperación internacional}

Excelentes resultados dan las políticas de cooperación basadas en la oferta de plazas y becas para cursar estudios en centros de enseñanza de países desarrollados. Superando anteriores reservas, la invitación a cursar estudios en instituciones militares de enseñanza de países occidentales se ha convertido en una de las medidas de confianza más creíbles de los últimos tiempos. En uno de los últimos cursos organizados por el NATO Defense College en Roma, 9 miembros de países del extinto Pacto de Varsovia -a los que se añadirían otros 26 durante el curso integrado PfP/OSCE- compartieron durante seis meses el curriculum académico de 60 altos oficiales y diplomáticos de países de la OTAN ${ }^{39}$. En España, en los últimos diez años, se han concedido 1038 becas a alumnos precedentes de países iberoamericanos; 468 a alumnos procedentes de países del Norte de Africa; 9 para alumnos asiáticos; y 23 para financiar los planes de estudios de otros tantos alumnos procedentes de países PECOS - denominación reservada a las naciones de Europa Central y Oriental-. En total, España ha concedido en los últimos diez años 1.538 becas que contribuyeron a completar la formación adquirida en sus países de origen por otros tantos mandos de fuerzas armadas de PVD.

La distribución regional de las becas proporciona una información del mayor interés sobre los intereses geopolíticos españoles basados, en su mayor parte, en profundos lazos históricos (Cuadro 2). Con independencia de los países PECOS - todos aspirantes a ingresar en la Alianza Atlántica o nuevos miembros de esta organización-, incluso las becas concedidas a países asiáticos lo fueron para Filipinas durante los cursos escolares 88/89, 97/98 y 98/99. Si pudiéramos echar un vistazo al número y distribución de plazas y becas concedidas por los Estados Unidos de América, en el mismo período, constataríamos sin duda que la distribución por todo el planeta se correspondía con el papel hegemónico que desempeña esta nación en la actualidad.

Pero, en esta clase de políticas, lo importante no es el «para» del curso, dado que, en términos de aprendizaje, los resultados son superados frecuentemente por los obtenidos en los centros de enseñanza nacionales, sino las ventajas inherentes a hacer los cursos «en». Para el país organizador constituye un insuperable instrumento de difusión de la propia cultura, al tiempo que fuente de enriquecimiento con las aportaciones personales de los oficiales y suboficiales invitados.

Ya sea por su pertenencia a círculos de poder, ya por sus cualidades profesionales, en las fuerzas armadas de muchos países del Tercer 


\section{El tercer mundo y las Fuerzas Armadas}

CUADRo 2. Programa de colaboración con otros países en materia de enseñanza militar. Becas concedidas por años y grupos de países

\begin{tabular}{|l|r|r|r|r|r|r|r|r|r|r|r|r|}
\hline \multicolumn{1}{|c|}{ ZONA } & $88 / 89$ & $89 / 90$ & $91 / 91$ & $91 / 92$ & $92 / 93$ & $93 / 94$ & $94 / 95$ & $95 / 96$ & $96 / 97$ & $97 / 98$ & $98 / 99$ & Total \\
\hline $\begin{array}{l}\text { IBEROA- } \\
\text { MERICA }\end{array}$ & 113 & 129 & 105 & 120 & 105 & 91 & 59 & 67 & 78 & 88 & 83 & 1.038 \\
\hline MAGREB & 0 & 13 & 20 & 58 & 51 & 59 & 68 & 61 & 42 & 54 & 54 & 468 \\
\hline ASIA & 3 & 0 & 0 & 0 & 0 & 0 & 0 & 0 & 0 & 1 & 1 & 9 \\
\hline PECOS & 0 & 0 & 0 & 0 & 0 & 0 & 0 & 0 & 1 & 9 & 9 & 23 \\
\hline TOTAL & 116 & 142 & 125 & 178 & 156 & 150 & 127 & 128 & 121 & 152 & 152 & 1.538 \\
\hline
\end{tabular}

Fuente: Ministerio de Defensa.

Mundo los aspirantes a cursar estudios en el extranjero son sometidos a un riguroso proceso de selección. Sin que sea una exclusiva de la formación militar ni una peculiaridad que sólo puede encontrarse en los PVD, lo cierto es que estos aspirantes ven mejorar su preparación y su curriculum de una forma que les abre nuevas posibilidades en aquellos ejércitos en los que la promoción no se base solamente en criterios de permanencia o antigüedad. Con el paso de los años, estos mandos acaban, en muchos casos, ocupando puestos de responsabilidad en sus respectivas organizaciones defensivas, lo que facilitará la cooperación entre países, la resolución negociada de conflictos, el entendimiento y la mutua comprensión.

Pero como ya se ha indicado, la principal contribución a la estabilidad y al progreso se obtiene por el hecho en sí de perfeccionar la formación personal en el seno de sociedades que regulan las relaciones entre sus ciudadanos por normas democráticas. Durante los meses que duren los estudios de estos oficiales y suboficiales se multiplicarán las oportunidades de convivir con otros que no se sienten especial e institucionalmente preocupados por problemas de política doméstica, más allá de lo que lo estén el resto de sus conciudadanos; ni que, ausentes del ejercicio del poder, se vean zarandeados por llamamientos a intervenir para solucionar problemas internos. Al final de este periodo, algunos oficiales se llevarán a sus naciones la certeza de que la democracia es el menos malo de los sistemas políticos; y que aunque los sistemas electorales en los regímenes democráticos no garantizan que los sabios lleguen al poder, sino los más hábiles, tampoco los 
sistemas autoritarios garantizan que los sabios lleguen al poder, sino los más duros. Aprenderán que, en las democracias, el sistema de adopción de decisiones es más complejo e interviene más gente, lo que aumenta la probabilidad de que entre ellos sí haya sabios. También verán que se tiene muy en cuenta lo que es percibido como bueno por la mayoría del cuerpo electoral, esto es, por los ciudadanos. Percibirán, por consiguiente, que hay más sabiduría en las decisiones de los gobiernos democráticos que en las de los regímenes autoritarios, aunque no sean aquellos los más sabios. La oportunidad de adquirir esta experiencia vital justificaría los recursos económicos destinados a financiar estos programas de cooperación; y sus rendimientos, en términos de estabilidad, estarán muy por encima de sus costes.

En resumen, y como ejemplo de las ventajas de mantener abiertas las vías de cooperación con los países menos avanzados del Tercer Mundo están: la oportunidad de relativizar la propia experiencia vital, el desplazamiento de la atención desde los problemas domésticos a los de seguridad internacional, el olvido del miedo interior como fundamento de la autoestima ${ }^{40}$, la consideración de la defensa como una función cuya responsabilidad y riesgos asociados a carencias defensivas debe compartir toda la sociedad.

\section{Ejemplos de cooperación en Africa. La iniciativa RECAMP}

Nacidas de la dificultad de actuar en tiempo de impedir catástrofes humanitarias, como las sucedidas en Ruanda, Somalia y Congo-Brazzaville, estas iniciativas han supuesto una novedosa vía de cooperación donde el protagonismo se mantendrá en las manos de organizaciones regionales - fundamentalmente la Organización para la Unidad Africana (OUA)-, limitándose el papel de las naciones occidentales que quieran participar en cada iniciativa a proporcionar recursos financieros, formación y equipo militar.

El Reino Unido dirigió sus esfuerzos a la organización de seminarios de operaciones de paz para ayudar a la OUA a mejorar su capacidad de preparar y desplegar unidades africanas de mantenimiento de la paz. Francia decidió, en la conferencia Francófona de Biarritz, de 1994, apoyar la creación de una Fuerza Africana de Intervención Rápida. Y los Estados Unidos, por su parte, dedicaron sus esfuerzos a la creación de una Fuerza de Respuesta a Crisis Africanas, iniciativa que fue perdiendo perfil hasta cristalizar en un limitado programa de adiestramiento. 


\section{El tercer mundo y las Fuerzas Armadas}

La opción francesa, fruto de la necesidad de coordinar todos estos esfuerzos, lo constituye la iniciativa RECAMP.

Con estas siglas se designa el concepto de «Refuerzo de las Capacidades Africanas para Misiones de Paz», una iniciativa de París desarrollada con la colaboración del Reino Unido y de los Estados Unidos, a los que recientemente se ha sumado España. Estas naciones decidieron, en 1997, unir sus esfuerzos para proporcionar a los países africanos un instrumento de seguridad colectiva propio y especializado en la resolución de conflictos en este continente.

Centrada en el campo de operaciones de mantenimiento de la paz bajo mandato de las Naciones Unidas, se identificaron tres áreas principales de cooperación: apoyo a la enseñanza especializada en misiones de paz, preposicionamiento de equipo para dotar a unidades multinacionales africanas y adiestramiento en ejercicios, donde se probaría el concepto.

Una de las primeras medidas adoptadas ha sido la apertura de una Escuela de Mantenimiento de la Paz en Costa de Marfil. Como en el caso de la OTAN para los conflictos territoriales entre países miembros (Grecia y Turquía), la creación de espacios comunes de interés y foros donde discutir y tratar desencuentros entre naciones es un aspecto que trasciende de la expectación creada por aquellos beneficios que aconsejaron adoptar tales iniciativas de cooperación internacional. El trabajo en común promueve oportunidades de diálogo, y éste es un imprescindible requisito del conocimiento, la comprensión y el respeto. Ésta es la mejor contribución que la cooperación internacional puede hacer a la creación de medidas de confianza que ayuden a superar, de una vez por todas, la ancestral incapacidad del ser humano para resolver por medios pacíficos sus conflictos.

El 19 de mayo de 1999, un diario español ${ }^{41}$ se hacía eco de un informe de la OCDE en el se aseguraba que Europa relevaría en el año 2000 a EE UU como motor económico internacional. En el mismo informe, se anunciaba que Japón permanecería un año más en recesión y se hacían los peores augurios para las economías de América Latina. En el caso de Brasil — continuaba el informe - se añadía que encabezaría el retroceso en el crecimiento de toda la región.

¿Quién puede predecir lo que pasará en el año 2050? Tratándose de liderazgos, al menos el de los EE UU en la segunda mitad del siglo XX lo fue de un país con doscientos años de tradición democrática. Debería haber una preocupación generalizada por adoptar todas las iniciativas que sean necesarias para garantizar similar tradición entre los candidatos a liderar el mundo en un futuro. 


\section{Juan Carlos Domingo Guerra}

\section{Notas}

1 Los otros países citados son: Argentina, Brasil, Grecia, Hong Kong, México, Singapur y Taiwan.

2 "Informe sobre Desarrollo Humano", Editorial Mundi-Prensa, Madrid 1998. El último informe relega a España al puesto 21 (HDI de 0,894) como consecuencia de la modificación de los criterios aplicados para calcular el índice.

3 Michel P. TODARo, «Economic Development», 6. ${ }^{a}$ edición, pág. 38, Universidad de Nueva York, 1997.

4 Datos de los Informes de Desarrollo Humano, Programa de la ONU para el Desarrollo, citados por M. Todaro, ibid., pág. 42.

5 "Atlas Mundial Microsoft Encarta», Edición 1999. Los datos que corresponden a aparatos informáticos son de 1996; los de servidores de Internet, de 1997.

6 Ibid. Los datos relacionados con el número de receptores de TV por cada 1000 habitantes corresponden a 1996.

7 Castellanización de la pronunciación de la palabra inglesa «truck» (camión).

8 Lleno, en Inglés.

9 SAmi NAÏr, "El continente olvidado», artículo publicado el 19 de marzo de 1999 en El País, pág. 15.

10 «La reducción de la 'modernización' de las sociedades al desarrollo económico, de éste al crecimiento, del crecimiento a la inversión productiva, sigue una línea de efectos mecánicos que, desgraciadamente, nunca tiene lugar en las sociedades pobres: la modernización se hace a menudo intolerable...». Ibid.

11 Michel P. TODARo, ibid., pág. 508.

12 El Banco Mundial citaba en 1992 como severamente endeudados a Argelia, Argentina, Bolivia, Brasil, Bulgaria, Congo, Costa de Marfil, Ecuador, México, Marruecos, Nicaragua, Perú, Polonia, Siria, Venezuela y Nigeria.

13 Programa de las Naciones Unidas para el Desarrollo (PNUD), 1997.

14 Mozambique, Etiopía, R. D. del Congo, Chad, Burundi, Tanzania, Sierra Leona, Ruanda, Nepal, Níger, Malawi, Burkina Faso, Sudán, Guinea-Bissau y Bangladesh.

15 India, Pakistán, Chile, Argentina, Perú, Colombia, Israel, Egipto, Siria, Irán, Irak, Arabia Saudita, Kuwait, Grecia y Turquía.

16 Alemania, Bélgica, Canadá, Dinamarca, EE UU, España, Francia, Grecia, Holanda, Italia, Luxemburgo, Noruega, Portugal, Reino Unido y Turquía.

17 ViveK B. ARora \& TAMim A. Bayoumi, "Reductions in World Military Expenditure: Who Stands to Gain", Finance \& Development, 1994.

18 SAADET DEGER, «Economic Development and Defense Expenditure», Economic Development and Cultural Change, The University of Chicago, 1986, pág. 193.

19 Emile BENOIT, "Growth and Defense in Developing Countries", Economic Development and Cultural Change 26, enero de 1978, pág. 271 y siguientes.

20 SAADET DEGER, ibid., pág. 194.

21 Guerra de Vietnam.

22 "Las legendarias carreras de Ingeniería y Arquitectura, más allá de nuestras fronteras», Tribuna de Actualidad, junio de 1996, pág. 32.

23 Michel P. TODARO, ibid.

24 Simón Bolívar, Kemal Ataturk.

25 Guerra de las Malvinas, entre Argentina y el Reino Unido. Conflicto de Cachemira, entre India y Pakistán. 


\section{El tercer mundo y las Fuerzas Armadas}

26 Israel (este Estado se creó en 1948).

27 Israel, Taiwan, en la segunda mitad del siglo XX.

28 PRUDENCIO GARCíA, "Ejército: presente y futuro», Alianza Editorial, pág. 39 y siguientes.

29 DiEgo AzQUETA, «Desarrollo y subdesarrollo», Fundación Argentaria, Madrid 1996.

30 Ibid. , pág. 17.

31 M. WEBER, "Economía y Sociedad".

32 Revolución de los Claveles, en Portugal.

33 Para el estudio de aquellos casos en los que la tutela del ejército se ha hecho efectiva por vía de su reconocimiento en el texto constitucional, basta con analizar las garantías de mantenimiento de Turquía como un Estado laico.

34 «Para que realmente existan mercados, y para que estos funcionen de un modo aceptable, se requieren instituciones sólidas, eficaces y creibles, lo que raramente se da en los países menos desarrollados». Economía, confianza, instituciones, artículo de Xosé Carlos ARIAS publicado en El País, el 20 de marzo de 1999.

35 Embargo decretado por la ONU a Irak.

36 En 1998, un oficial español que asistía en calidad de alumno a un curso en un país africano se vio sorprendido por el comentario de una compañera de curso, oficial de un PVD: "Es un placer hablar con Vd.,... porque me escucha». El oficial español no había renunciado a valores democráticos de igualdad y había sido recompensado, al menos, con el reconocimiento a su actitud en un ambiente en el que, quizás, hubieran extrañado menos otros comportamientos.

3750.000 muertos lleva ya en su particular cuenta la guerra entre Eritrea y Etiopía. Alrededor de 2 millones han perecido en Sudan. Son datos del Centro Carter, de los EE UU.

$38 \mathrm{Y}$ también responde a las leyes de oferta y demanda. La guerra de Kosovo obligó al Pentágono a cancelar 6.000 retiros programados y a ampliar el número de plazas de la reserva.

39 Al Senior Course 93, curso académico 98-99, asistieron representantes de la República Checa, Georgia, Hungría, Lituania, Moldova, Polonia y Rusia. Al curso integrado del programa Partnership for Peace y OSCE (IPOC 98/2), de una semana de duración, asistieron otros 26 representantes de los siguientes países: Albania, Austria, Azerbaiyán, Bulgaria, Estonia, Finlandia, FYROM, Georgia, Hungría, Lituania, Moldova, Polonia, Rumania, Eslovaquia, Eslovenia, Suiza, Rusia, Ucrania y Uzbekistán. SPOTLIGHT, $11^{\mathrm{a}}$ edición, febrero 1999 , pág. 3 .

40 La degeneración de un ejército se hace patente cuando desfila para amedrentar a su propio pueblo.

41 El País, 19 de mayo de 1999, pág. 63. 